\title{
GLANDULAR SOURCES AND SPECIFICITY OF SOME CHEMICAL RELEASERS OF SOCIAL BEHAVIOR IN DOLICHODERINE ANTS ${ }^{1}$
}

\author{
By Edward O. Wilson ${ }^{2}$ and Mario Pavan ${ }^{3}$ \\ Introduction
}

Species of the ant subfamily Dolichoderinae are excellent subjects for the experimental analysis of chcmical communication. The group is advanced evolutionarily, and large, complex societies are the rule. During foraging, workers of many species form long, conspicuous columns tightly bound to persistent odor trails. When disturbed they void volatile secretions that seem likely to function, at least in part, as olfactory releasers of alarm behavior. Furthermore, the dolichoderines have recently been the object of extensive biochemical research by Pavan, Cavill and their associates (cf. Pavan, I950; Pavan and Ronchetti, I955; Pavan and Trave, I958; Cavill, Ford, and Locksley, 1956; Cavill and Locksley, 1957). Several terpenoids including the previously unknown iridomyrmecin, iso-iridomyrmecin, and iridodial, have been identified as components of the anal gland secretion of various species. The availability of these substances in purified form has made possible for the first time the precise behavioral assay of natural secretory products in ants.

\section{Trail Substances}

Applying the artificial trail technique used earlier by one of us (Wilson, 1959) in studies of the myrmicine Solenopsis saevissima, an attempt was made to determine the glandular source of the trail substance in workers of Iridomyrmex humilis Mayr. Groups of workers from laboratory colonies (grown from stocks originating from Baton Rouge, Louisiana) were attracted to drops of I $M$ sucrose solution, about $6 \mathrm{~mm}$ in diameter, on glass feeding tables. Selected body parts of freshly killed workers were made into artificial trails directed at the feeding workers. The number of workers following the trails beyond the trail midpoint, i.e., $15 \mathrm{~cm}$. from the sucrose bait, were recorded. When positive responses were obtained, the duration of biological activity was timed to the nearest half-minute. Preliminary experiments showed that the trail substance is limited to the abdomen,

\footnotetext{
${ }^{1}$ Based on research supported in part by a grant from the U. S. National Science Foundation.

${ }^{2}$ Biological Laboratories, Harvard University, Cambridge, Mass., U. S. A.

${ }^{3}$ Istituto di Anatomia Comparata and Istituto di Entomologia Agraria dell'Universitá di Pavia, Italy.
} 
smears from other body parts proving consistently inactive. This result was not unexpected, since humilis workers can be clearly seen to drag the posterior portion of the abdomen over the ground while in the act of laying trails.

Five organs in the abdomen are capable of emptying glandular secretions to the outside: ( I ) the hind-gut; (2) the paired "true" poison glands, with a large reservoir, the poison vesicle; (3) Dufour's gland (also called the accessory gland) ; 4 ) the anal glands, opening just above the anus; (5) the glandular "ventral organ" recently discovered by Pavan (1955). In a series of experiments, the five organs were dissected out of freshly killed workers, washed in insect Ringer's solution, and bioassayed with artificial trail tests. The results, summarized in table I, show that the bulk, and perhaps the entirety, of the trail substance resides in the ventral organ. The occasional weak

TABLE 1. Results of artificial trail assay of selected abdominal organs of Iridomyrmex humilis workers.

\begin{tabular}{|c|c|c|c|c|}
\hline Organ & $\left|\begin{array}{l}\text { Number } \\
\text { of tests }\end{array}\right|$ & $\left|\begin{array}{l}\text { Number of } \\
\text { positive } \\
\text { responses* }\end{array}\right|$ & $\begin{array}{l}\text { Number of workers } \\
\text { responding: range } \\
\text { (with mean) }\end{array}$ & $\begin{array}{l}\text { Duration of re- } \\
\text { sponses in minutes: } \\
\text { range (with mean) }\end{array}$ \\
\hline hind gut & 6 & 0 & $0-2 \quad(M<1)$ & $0-1 / 2(M<1 / 2)$ \\
\hline $\begin{array}{l}\text { true poison } \\
\text { glands, plus } \\
\text { reservoir }\end{array}$ & 6 & 0 & $0-2(M<1)$ & $0-1 / 2 \quad(M<1 / 2)$ \\
\hline $\begin{array}{l}\text { Dufour's } \\
\text { gland }\end{array}$ & 8 & 2 & $0-30 \quad(M=8)$ & $0-4(M=1)$ \\
\hline anal gland & 5 & 1 & $0-15 \quad(M=6)$ & $0-1 \quad(M=1)$ \\
\hline $\begin{array}{l}\text { ventral } \\
\text { organ }\end{array}$ & 7 & 7 & $\begin{array}{l}65-339 \\
(M=134)\end{array}$ & $2-9 \quad(M=5)$ \\
\hline
\end{tabular}

* Positive responses are defined, arbitrarily, as the crossing of the trail midpoint by 10 or more workers.

responses to the contents of the Dufour's and anal glands may not be biologically significant, i.e., may not indicate the presence of substances normally secreted into the trail, since responses of comparable magnitude have been obtained with pure methylheptenone, a substance not known to occur in humilis workers.

In a second series of experiments, the ventral organ and anal glands of Iridomyrmex pruinosus (Roger) ${ }^{4}$ were assayed. As in humilis, the ventral organ smears caused strong trail following while re-

\footnotetext{
${ }^{4}$ Collected at Baton Rouge, Louisiana.
} 
sponses to anal glands were negligible. Furthermore, artificial trails made with 2-heptenone, the anal gland secretion of pruinosus (M. S. Blum, in litt. ), caused negligible responses.

In a third series of experiments, the hind-gut, poison apparatus, Dufour's gland, and ventral organ were assayed in a laboratory colony of the primitive dolichoderine Monacis bispinosa (Olivier).! The unusually restless and aggressive nature of the Monacis workers required the following modification in procedure. Straight trails $75 \mathrm{~cm}$. in length were drawn down the middle of a clean glass plate. Three workers were then released, one at a time, and allowed to wander over the glass plate, crossing and re-crossing the trail. A positive response was recorded when the worker persistently followed the trail to its end. Of 18 workers thus exposed to trails made successively from 6 ventral organs, I 7 gave positive responses. The responses of workers in triplicated control experiments using the other abdominal organs were all negative.

After the chief source of the odor trails in the three dolichoderine species had been located, bioassays were made across species, in order to determine the extent of species-specificity of the trail substances. As shown in table 2, each species appears to have a different substance.

TABLE 2. Intra- and interspecific trail-substance tests employed in the present study. Only intraspecific tests produced positive responses $(+)$. The results of all interspecific tests employed were negative $\left({ }^{--}\right)$. Interspecific tests not attempted are indicated by a question mark.

\begin{tabular}{|c|c|c|c|c|c|}
\hline \multirow[t]{2}{*}{ Source } & \multicolumn{5}{|c|}{ Recipient } \\
\hline & Monacis & Liometopum & Iridomyrmex & $\begin{array}{c}\text { Iridomyrmex } \\
\text { pruinosus }\end{array}$ & Tapinoma \\
\hline M. bispinosa & + & ? & - & ? & sessile \\
\hline L. occidentale & $?$ & + & - & ? & - \\
\hline I. humilis & 一 & - & + & - & - \\
\hline I. pruinosus & ? & ? & - & + & - \\
\hline T. sessile & - & ? & - & $?$ & + \\
\hline
\end{tabular}

Further, the Dufour's glands and ventral organs of Monacis bispinosa were assayed with laboratory colonies of the myrmicine ants Crematogaster lineolata (Say), Solenopsis geminata (Fabr.), and S. saevissi$m a$ (Fr. Smith). The ventral organ induced no detectable response in these species. The Dufour's gland caused no response in the Crematogaster but, quite unexpectedly, caused strong trail-following in Solenopsis saevissima! In fact, single Monacis glands consistently drew out approximately the same number of $S$. saevissima workers as single saevissima glands. It was also determined that a single Monacis

\footnotetext{
${ }^{5}$ Collected at Palmar, southern Costa Rica.
} 
Dufour's gland caused a weaker response in $S$. geminata, well below the intensity caused by a geminata gland and approximately the same as that caused by a saevissima gland (see Wilson, 1960). These results are interpreted as indicating the chemical identity, or nearidentity, of the Monacis bispinosa and Solenopsis saevissima Dufour's secretions. Curiously, the Solenopsis use the secretion as a trail substance, but the Monacis do not. The function of the secretion in Monacis remains unknown.

Some further comment is needed concerning the organ we are here referring to as the ventral organ. The gland was discovered in Iridomyrmex humilis by Pavan (1955) and described in greatcr detail by Pavan and Ronchetti (1955). It is a paddle-shaped organ resting on the ventral body wall just over abdominal sternite VI (sternite IV of gaster). It opens posteriorly via a ncck-like constriction between the VI and VII abdominal sternites. The opening is fitted with an unusual beak-shaped deformation of the posterior border of sternite VI, a structure seemingly designed to guide the effluence of the gland contents. Until the present experimental work, the function of the gland remained unknown, although Pavan and his associates suggested that it produced either the trail substance or a secondary defensive secretion. Additional morphological studies by Miradoli $Z$ atti and Pavan (1957) disclosed the presence of a closely similar gland in the primitive dolichoderine genera Ancuretus and Leptomyrmex. In the course of subsequent work we have noted its presence in Monacis bispinosa and Hypoclinea doriae Emery as well. The ventral organ appears to be peculiar to the Dolichoderinae and Aneuretinae and hence can serve as a valuable diagnostic character for these two closely allied groups. If it serves as the source of the trail substance in all of the dolichoderine tribes (and in the ancestral aneuretines), as the preliminary evidence suggests, it can be interpreted as a remarkable example of a "social organ" cvolved de novo with the specific function of mediating worker communication.

\section{Alarm Substances}

When colonies of Tapinoma sessile, Liometopum occidentale, and Monacis bispinosa are disturbed by opening the nest, workers rclease considerable quantities of secretions from their anal glands which can be easily smelled by the human observer. When the anal glands are removed from freshly killed workers of these species and their contents released in the presence of groups of resting live workers, the latter are thrown instantly into a typical alarm frenzy, indistinguish- 
able from that caused by direct mechanical disturbance. Other body parts tested in this manner do not induce the same reaction. Although the volatile components of the anal glands of each species produce a distinctly different smell to humans, there is evidently no species-specificity shown in the alarm response. Unlike the complete specificity shown in responses to trail substances, squashes of anal glands of each species produce approximately the same intensity of alarm curiosity in workers of the other two species as in its own. These results can be interpreted as indicating that either a common component exists in each of the anal secretions or else, as seems more likely, the secretions differ but the reactions are not species-specific.

In contrast, disturbed workers of Iridomyrmex humilis do not release quantities of volatile substances sufficient to be detected by the human observer. Moreover, they do not respond with more than mild. excitement to single anal-gland squashes from sister workers or the other three dolichoderine species.

Pavan and Trave (1958) have shown that the volatile components of anal gland secretion of Tapinoma nigerrimum (Nylander) are methylheptenone $\left(\mathrm{C}_{8} \mathrm{H}_{14} \mathrm{O}\right)$ and propyl-isobutyl-ketone $\left(\mathrm{C}_{8} \mathrm{H}_{16} \mathrm{O}\right)$. Since our initial experiments suggested that the action of alarm substances is not species-specific, it was not surprising to find that small quantities of the two nigerrimum substances, manufactured synthetically and presented in separate tests, caused intense alarm behavior in Tapinoma sessile. No attempt has been made to map the full range of compounds that will induce the alarm frenzy in the dolichoderines that communicate alarm by anal secretions. However, the following preliminary study will show that not all volatile ant secretions have this effect. A simple olfactometer test designed to measure mass response in laboratory colonies of Solenopsis saevissima (cf. Wilson, 1960) was applied to a small (300-worker) colony of Tapinoma sessile. The tested compound was allowed to evaporate from a 15 $\mathrm{mm}^{2}$ film into a nest inlet into which air was being gently drawn. The maximum increase, if any, of workers outside the nest was then measured during the ensuing five minutes. Each substance was tested three times. Tests were spaced at least two hours apart to reduce habituation, and substances were presented in irregular order to prevent special sequential effects. Formic acid, a common defensive abdominal secretion of formicine ants, caused either no visible response or very mild excitement in the nest, and increased the outside worker force by only 3-8. Concentrated Dufour's gland secretion of Solenopsis saevissima, which induced a mass exodus of saevissima 
workers in similiar tests, caused in Tapinoma sessile either no visible effect or mild excitement in the nest, and increased the outside worker force from minus-I to 9. A mixture of nepetalactone (oil of catnip) and oil of peppermint caused mild excitement in the nest and an exodus of 2 to 24 workers. Propyl-isobutyl-ketone caused mild to intense excitement in the nest and an exodus of 12 to 23 workers; many of the workers were in maximum intensity of excitement and ranged widely over the foraging table. Methylheptenone caused mild to intense excitement in the nest, and an exodus of 4 to 69 workers, many of which were maximally excited and ranged widely over the foraging table. In one trial using methylpeptonone, a queen, several callows, and other workers carrying brood also left the nest temporarily.

In two subsequent experiments, small Tapinoma sessile colonies were exposed in the manner just described to prolonged doses of methytheplenone. In both cases, excitement within the nest and individual worker exodus declined to about the normal level within Io minutes. Shortly afterward, however, workers began mass movements along odor trails to secondary shelters away from the main nest. Within 90 minutes almost the entire colony had emigrated to the new nest sites, leaving behind only a few workers in the main nest.

\section{Summary}

In Iridomyrmex humilis Mayr, I. pruinosus (Roger), and Monacis bispinosa (Olivier), representing two genera phylogenetically far apart in the Dolichoderinae, the principal or exclusive source of the odor trail is the ventral organ, an exocrine gland opening behind abdominal sternite VI. Cross-species tests were made with the odor trails of these species and of Liometopum occidentale Emery and Tapinoma sessile Say. The trail-substances were found to be speciesspecific. The ventral organ is peculiar to the Dolichoderinae and the ancestral Aneuretinae, and it is interpreted as an example of a "social organ" that has been evolved de novo as part of the colonial communication system.

Volatile alarm substances are produced in the anal glands of each of the species except Iridomyrmex humilis. These releasers are not species-specific. The volatile anal secretions of Tapinoma nigerrimum, methylheptenone and propyl-isobutyl-ketone, when tested with workers of Tapinoma sessile, produced typical alarm behavior. Prolonged exposure induced colony emigration, which was then organized by the laying of odor trails. 


\section{REFERENCES}

Cavill, G. W. K., D. L. Ford, and H. D. Locksley. (1956). The chemistry of ants. I. Terpenoid constituents of some Australian Iridomyrmex species. Australian J. Chem., 9 (2) : 288-293.

Cavill, G. W. K. and H. D. Locksley. (1957). The chemistry of ants. II. Structure and configuration of iridolactone (isoiridomyrmecin). Australian J. Chem., $10(3): 352-358$.

Miradoli Zatti, M. A. and M. Pavan. (1957). Studi sui Formicidae. III. Nuovi reperti dell'organo ventrale nei Dolichoderinae. Boll. Soc. Ent. Ital., $87(5-6): 82-87$.

Pavan, M. (1950). Potere Insetticida della iridomyrmecina e significato della sostanza vella biologia di Iridomyrmex humilis Mayr. La Ricerca Scientifica, 20 (12) : 1853-1855.

(1955). Studi sui Formicidae. I. Contributo alla conoscenza degli organi gastrali dei Dolichoderinae. Natura, 46: 135-145.

Pavan, M. and G. RonchetTi. (1955). Studi sulla morfologia esterna e anatomia interna dell'operaia di Iridomyrmex humilis Mayr e richerche chimiche e biologiche sulla iridomirmecina. Att. Soc. Ital. Sci. Nat., 94 (3-4) : 379-477.

Pavan, M. and R. Trave. (1958). Études sur les Formicidae. IV. Sur le venin du Dolichoderide Tapinoma nigerrimum Nyl. Insectes Sociaux, 5 (3) : 299-308.

WiLson, E. O. (1959). Source and possible nature of the odor trail of fire ants. Science, 129: 643-644.

(1960). Chemical communication among workers of the fire ant Solenopsis saevissima (Fr. Smith). Animal Behaviour (in press). 

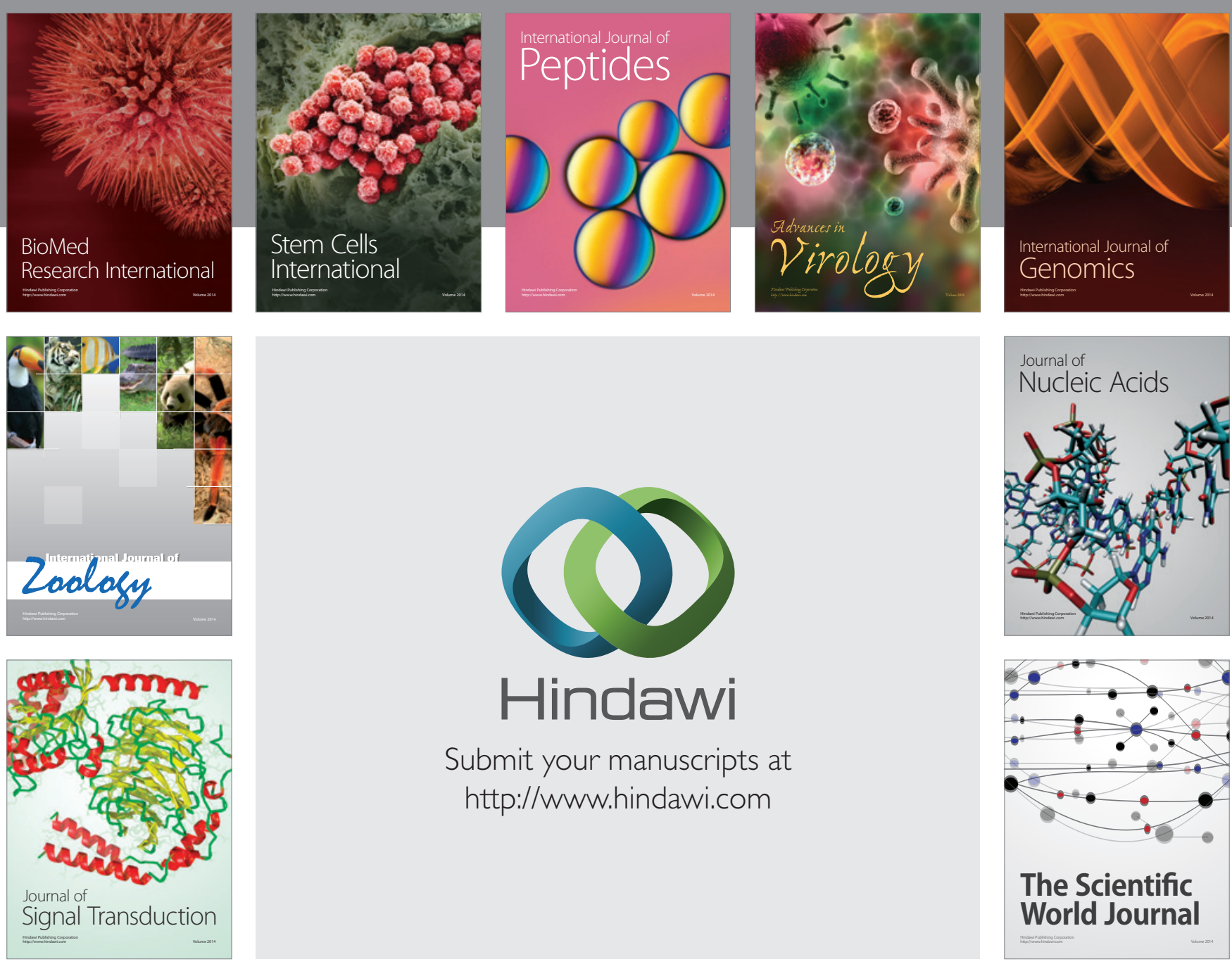

Submit your manuscripts at

http://www.hindawi.com
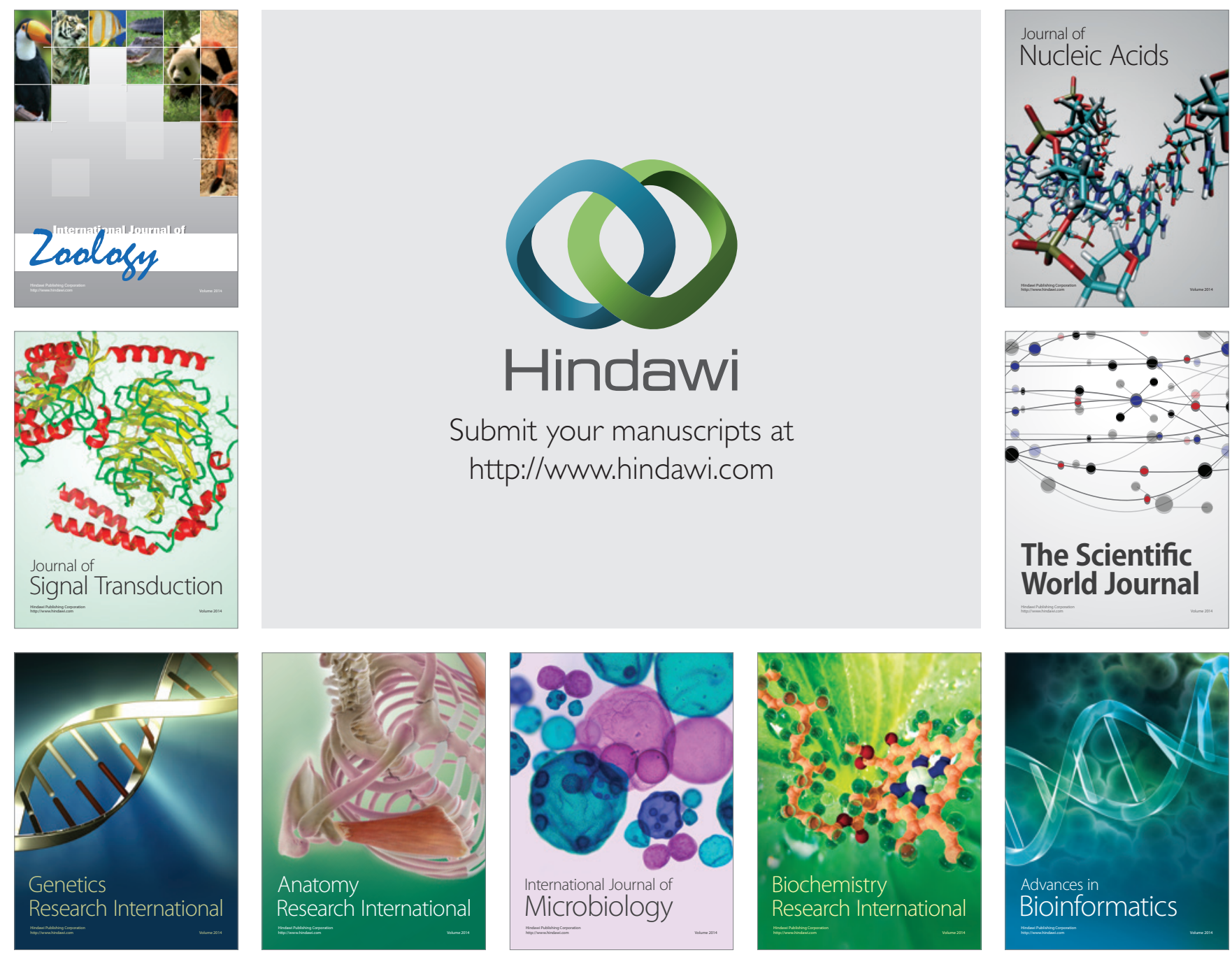

The Scientific World Journal
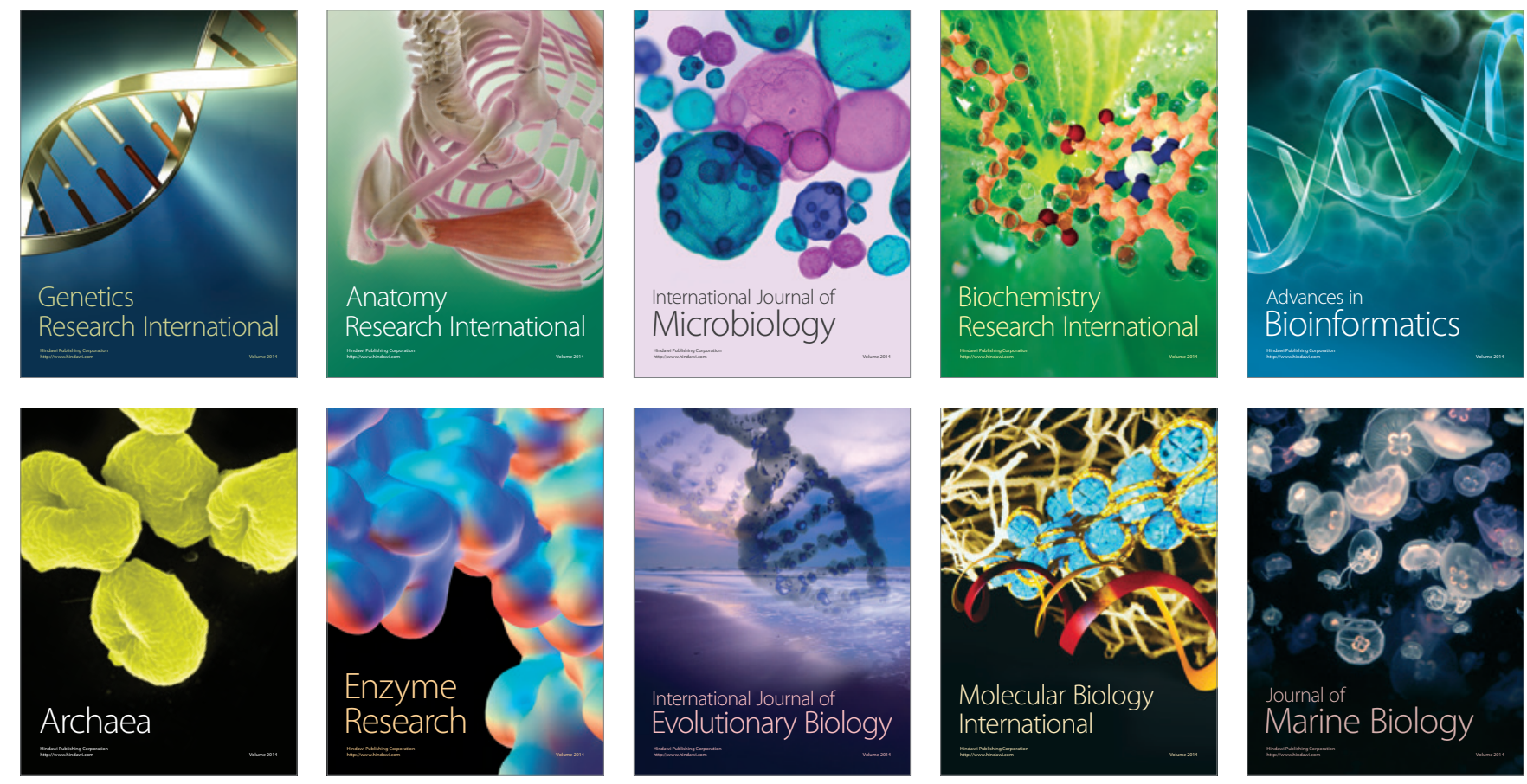